\title{
Article
}

\author{
지방어항개발의 투자결정요인 분석 \\ - 충청남도 어항 중심으로 - \\ 이광남 $^{1^{*}} \cdot$ 정진호 $^{1} \cdot$ 최재욱 $^{2}$ \\ 1한국수산회 수산정책연구소 \\ (137-940) 서울시 서초구 양재동 275-1 \\ 2농림수산식품기술기획평가원 사업관리실 \\ (431-060) 경기도 안양시 동안구 부림로 166
}

\section{A Study on Decisions on Investment Factors in the Development of Local Fishing Harbors}

\author{
Kwang-Nam Lee ${ }^{1 *}$, Jin-Ho Jung ${ }^{1}$, and Jae Wook Choi ${ }^{2}$ \\ ${ }^{1}$ Korea Fisheries Association, Fisheries Policy Institute \\ Seoul 137-940, Korea \\ ${ }^{2}$ Project Management, iPET \\ Anyang 431-060, Korea
}

\begin{abstract}
In the recent WTO/DDA negotiations, discussions are progressing to forbid fishery subsidies which have negative effect on the natural environment and the fishery resources and to lower or to eliminate the tariff/non-tariff barriers that distort trade liberalization. As a result, linking to the weak structural environment of Korea's fishing villages; such a scheme has jeopardized the livelihood of fishermen who settle down in local fishing harbors. Against this backdrop, the government is attempting to positively respond to changes in the fishing environment in a number of different ways: promotion of fishing tourism, fishing harbor reinforcement in function, developing fishing villages, and harbors. With respect to investment by priority in fishing harbor development, it is very important to appropriately select investment targets based on objective criteria. A small number of harbors are chosen and investment plans by harbor are systematically devised, economic feasibility and the effects of investment are analyzed and reviewed in relation to each target harbor. This paper is designed to review and assess objective evaluation methods and the degree of importance for the designation of target harbors, dealing with local harbors in Chung Nam Do as a model. Each local government has tried to reorganize existing harbors and develop new harbors, considering a fall in the number of fishing vessels and the expansion of maritime leisure activities. In order to overcome the limit of existing harbors in function, to raise the income of fishermen, and to activate tourism, they have shifted their focus from simple functions such as vessel evacuation and anchoring to harbor beautification, which can work as a basis for fishing tourism. This paper points out that the AHP analysis method for prioritizing local harbors in Chung Nam Do should help to be chosen target harbors in other cities and provinces. Each local government has attempted to reorganize existing harbors and to develop new harbors, taking into consideration the decline in the number of fishing vessels and the expansion of maritime leisure activities. In order to overcome the limited number of functional harbors, to raise the income of fishermen, and to boost tourism, they have shifted their focus from simple functions, such as vessel evacuation and anchoring, to harbor beautification, which can work as a basis for fishing tourism. This paper shows that the AHP analysis method for prioritizing local harbors in Chungcheongnamdo could aid in the effective selection of target harbors in other cities and provinces.
\end{abstract}

\footnotetext{
*Corresponding author. E-mail : lkn6530@chol.com
} 
Key words : local fishing harbor, investment factors, livelihood of fishermen, fishing villages, AHP analysis

\section{1. 서 론}

최근 FTA, WTO/DDA 등 수산업을 둘러싼 대내외 환 경 변화에 따라 우리나라 어촌의 취약한 구조적 환경과 더불어 어촌어항에 정주하고 있는 어업인들의 생계를 더 욱 어렵게 하고 있다. 이러한 환경 속에 최근 정부에서는 어촌관광의 증대와 새로운 어항 기능의 수요증대 등 어촌 환경 변화에 능동적으로 대처하고, 어항과 어촌지역을 연 계 개발함으로써 낙후된 어촌소득기반시설 및 어촌정주환 경을 개선할 수 있도록 어항에 대한 종합적 개발에 대한 노력을 하고 있다.

어항개발에 대한 정책적 방향은 조업어선을 안전하게 수용하고 이용에 편리하도록 기존어항 조기완공 및 신규 어항 지정-개발을 기존 어항에 대한 지속적 정비·확장 (remodeling)으로 낙후어촌의 생활환경개선 및 소득원 창 출하는데 있다. 특히, 신규어항 개발은 단순한 수산업 기 반시설 외에 어촌의 생산-생활-문화의 공간 등을 갖춘 복합적인 종합어항으로 개발하는 것이 어항에 대한 중장 기 정책방향이다.

과거에는 어항이 수산물의 생산과 판매를 연결하는 1 차 산업의 기지 역할을 해 온 반면, 최근에는 어촌관광, 해상 레저, 친수공간을 제공하는 3차 산업의 중심지로 그 역할 이 확대되고 있다. 정부가 어항개발에 투입해 온 사업비는 58,240 억원으로 수산부문 재정투융자에서 가장 큰 비중을 차지하고 있다.

어항시설에 대한 투자는 꾸준히 증가하여 왔으나 어항
시설 투자에 대한 어항의 지정 및 경제적 효과와 관련한 연구는 거의 이루어지지 않았다. 한 등 $(2005)^{1)}$ 의 연구에서 평가모델에 대한 종합적인 검토가 이루어진 사례가 있다.

공공투자사업에 있어서 많은 연구자들이 합리적인 투자 우선순위를 결정하는 방법을 제시하고자 노력해오고 있 다. 임(1999)은 지방자치단체의 투자우선순위 결정과 재 원조달방안에 대한 연구에서 투자우선순위를 결정하는 과 정을 투자수요 파악단계, 경제적 타당성 검토단계, 사회적 타당성 검토단계의 세 단계로 구분하여 각 단계별 검토기 준을 통과하지 못한 투자사업은 예산편성에서 제외하는 방법을 채택하였다.

원과 박(2003)은 도로사업 우선순위 평가시 경제성 측 면 외에 재정자립도 및 지역간 통행시간을 반영하여 타 광역시도와 차별화하여 적용할 필요가 있다고 지적하였 다. 그러나 이들 연구에서 보듯이 구체적이고 합리적인 평 가근거의 중요성은 인식하나 이를 위한 구체적인 방법을 찾기가 쉽지 않은 것 같이 여겨진다. 이러한 가운데 많은 선행연구에서는 $\mathrm{AHP}$ 기법을 활용하여 그 해결책을 찾고 자 노력하였다.

$\mathrm{AHP}$ 기법에서는 최종의사결정에 도달한 과정을 명확 히 밝힘으로써 의사결정의 투명성을 보여준다. 또한, 이 기법을 이용하면 모형을 구성하는 평가항목을 다양한 사 업에 장기적으로 적용함으로써 사업간 평가의 일관성을 확보하여 공공투자 의사결정에 대한 신뢰도를 제고하는 효과를 얻을 수 있다.

$\mathrm{AHP}$ 기법을 이용한 연구들은 이 등(2002)의 국가연구

Table 1. Types of fishing harbor and authority

\begin{tabular}{|c|c|c|c|c|}
\hline & Classification & Number & Contents & Authority \\
\hline \multirow{3}{*}{ Legal } & $\begin{array}{l}\text { Nation harbor (Before 1st, } \\
\text { 3rd class harbor) }\end{array}$ & 110 & $\begin{array}{l}\text { - Nationwide harbor } \\
\text { - The harbor (is located backwoods) is needed to develop } \\
\text { fishery and vessel evacuation }\end{array}$ & MIFAFF \\
\hline & $\begin{array}{l}\text { Local fishing harbor } \\
\text { (Before 2nd class harbor) }\end{array}$ & 313 & - Local harbor is supported coastal fishery & $\begin{array}{l}\text { Cities, } \\
\text { Provinces }\end{array}$ \\
\hline & $\begin{array}{l}\text { Harbor of fishing } \\
\text { village settlement }\end{array}$ & 373 & - Small scale harbor with life base of fishing village & $\begin{array}{c}\text { Cities, } \\
\text { Countries, } \\
\text { District }\end{array}$ \\
\hline Non-legal & $\begin{array}{l}\text { Small scale } \\
\text { fishing harbor }\end{array}$ & 1,438 & - Harbor (Except registered harbor) & $\begin{array}{c}\text { Cities, } \\
\text { Countries, } \\
\text { District }\end{array}$ \\
\hline
\end{tabular}

Source: KFPA (http://www.fipa.or.kr).

1) 한광석, 이종훈. (2005) 어항개발의 경제성 평가분석 방법론에 관한 연구, 한국해양수산개발원, pp. 121-149; 한광석, 성상봉. (2009) 국가 어항개발사업 모니터링 조사보고서, 한국해양수산개발원, pp. 280 참조. 
Table 2. Types of fishing harbor and authority

\begin{tabular}{ccccc}
\hline Classification & Total project cost & Investment until 06 & Project 07 & Remaining budget \\
\hline Total & 58,240 & 31,115 & 2,102 & 25,023 \\
Nation harbor & 38,694 & 22,158 & 1,457 & 15,079 \\
Local harbor & 19,546 & 8,957 & 645 & 9,944 \\
\hline
\end{tabular}

Source: KFPA (http://www.fipa.or.kr).

개발사업의 투자배분방향수립을 위한 투자우선순위에 관 한 연구를 비롯하여 적정국방비 규모산출을 위한 연구(김 2003), 지방정부의 행정혁신 우선순위선정에 관한 연구 (양 2005), 스포츠산업 발전을 위한 우선투자요인에 관한 연구(권 2005) 등 정부투자사업과 관련된 연구 뿐 아니라 여러 분야에서 우선순위결정을 위한 연구에서 사용되고 있다.

본 연구에서는 AHP 기법을 이용하여 지방어항개발의 투자우선순위결정 및 평가기준을 제시하여 투자사업의 우 선순위를 결정하기 위한 방법을 찾아보고자 하였으며, 이 러한 시도는 어항 부문에 있어서는 처음 시도되는 것이다.

\section{2. 분석의 이론적 틀}

\section{어항의 개념 및 투자 현황}

어항법에서의 어항은 천연 또는 인공의 어업근거지가 되는 어항구역과 어항시설로서의 어항법 제6조의 지정·변 경 및 해제여건에 따라 지정된 어항을 의미한다.

어항은 어선이 안전하게 출입-정박하고 어획물의 양 륙, 선수품의 공급 및 기상악화시 어선이 안전대피할 수 있는 어업활동의 근거지 ${ }^{2)}$ 이며, 어항의 역할 및 기능을 살 펴보면, 첫째, 어선의 안전정박으로 어업인의 생명과 재산 보호, 어획물의 양륙장, 어구의 준비, 급유, 급수, 어선의 수리 등을 담당하는 출어준비장소의 역할을 하는 어업활 동지원기지이며, 둘째, 어획물의 하역 및 시장 거래, 소비 지 등으로 출하하는 수송 터미널, 수산가공업 기지 등 수 산물 유통기지 역할을 담당한다. 셋째, 어촌주민의 생활기 반과 어업관련산업을 주로하는 지역경제발전의 기반, 도 서, 벽지의 어촌과 외부사회를 잇는 교통, 정보의 기지로 어촌 등 지역사회기반시설로의 역할, 넷째, 해양관광 및 레크리에이션 장소, 바다문화 승계 및 바다체험 학습장소 로써 도시지역 주민의 휴식공간 등을 담당한다고 할 수 있다.

어항의 종류는 크게 국가어항, 지방어항, 어촌정주어항, 소규모 어항으로 분류할 수 있으며, 이 중 법정어항은 국 가어항, 지방어항, 어촌정주어항이 포함된다.
어항개발사업 투자현황을 살펴보면, 2006년까지 31,115 억원이 투자되었으며 2007년도에는 2,102억원으로 나타 났다. 여기에서 전사업비는 총 25,023 억원이며, 이는 어항 을 건설하는데 있어서 시간이 소요되므로 예산적 측면에 서의 사업비이다.

본 연구는 어항개발의 투자우선순위선정에 대하여 여러 어항 중 개발에 투자를 함에 있어서 객관적인 기준을 통 하여 선정이 되어야하는 데 대한 평가방법에 대하여 검토 하고자 하였다. 선정 대상항이 소수일 경우와 어항별 투자 계획이 체계적으로 설립되어 있는 경우에는 각 어항에 대 한 경제성 분석 및 투자파급효과 검토를 하며, 충청남도의 지방어항 지정을 사례로 어항개발 대상항의 지정을 위한 객관적인 평가방법 및 중요도를 평가하는 것을 목적으로 하였다.

\section{분석 대상 지방어항 현황}

일반적으로 어항개발 투자사업의 우선순위를 도출하기 위한 결정 요인은 시간과 환경에 따라 다양하게 변화하는 비구조화된 양식을 따르게 되며, 동 연구에서의 분석 대상 은 아래의 Table 3 과 같다. ${ }^{3)}$

\section{Table 3. Designated local harbor review}

\begin{tabular}{ccc}
\hline Classification & $\begin{array}{c}\text { Harbor of fishing } \\
\text { village settlement }\end{array}$ & Small scale harbor \\
\hline Boryeong-si & 2 & - \\
Taean-gun & 1 & - \\
Dangjin-gun & - & 2 \\
Seosan-si & - & 4 \\
Seocheon-gun & - & 2 \\
Hongseong-gun & - & 2 \\
\hline Total & 3 & 10 \\
\hline
\end{tabular}

\section{우선순위 산정방법}

\section{기존 방법에 의한 우선순위 산정}

지방어항 지정기준을 만족하는 12 개항에 대하여 평가 항목 및 배점기준에 의거 우선순위를 산정하였다.

2) 천연 또는 인공의 어업근거지가 되는 어항구역과 어항시설로서 어촌·어항법 제 17 조의 규정에 의하여 지정.

3) 충청남도 (2009) 지방어항 지정 타당성 조사, pp. 133-152. 
Table 4. Assessment item for priority decision

\begin{tabular}{|c|c|c|c|c|}
\hline Category & Item & Classification & Assessment & Remark \\
\hline \multirow{2}{*}{$\begin{array}{l}\text { Weather } \\
\text { conditions }\end{array}$} & Weather & $\begin{array}{l}\text { Temperature, precipitation, } \\
\text { wind, typhoon }\end{array}$ & - & \multirow{2}{*}{$\begin{array}{l}\text { The exclusion of } \\
\text { common item }\end{array}$} \\
\hline & Sea & Sea level, Tide, Wave & - & \\
\hline \multirow{7}{*}{$\begin{array}{l}\text { Fishing } \\
\text { industry } \\
\text { condition }\end{array}$} & \multirow{3}{*}{$\begin{array}{l}\text { Vessel } \\
\text { condition }\end{array}$} & Number of vessel and tons & Number of vessel and tons & - \\
\hline & & Outside vessel & Number of outside vessel & - \\
\hline & & Recreation fishing boat & Recreation fishing boat check & - \\
\hline & The & Fishery population & Fishery population & \\
\hline & $\begin{array}{l}\text { dependence } \\
\text { of fishing } \\
\text { industry }\end{array}$ & $\begin{array}{l}\text { Fishing amount, Catch of fish, } \\
\text { Fishery area, Right of fishery }\end{array}$ & $\begin{array}{l}\text { Fishing amount, Right of fishery } \\
\text { (Except for harbor limit) }\end{array}$ & \\
\hline & Compliance & $\begin{array}{c}\text { Counter facilities, Berthing facilities, } \\
\text { Harbour facilities }\end{array}$ & - & $\begin{array}{c}\text { The lack of facilities } \\
\text { standard }\end{array}$ \\
\hline & $\begin{array}{l}\text { Function } \\
\text { facilities }\end{array}$ & $\begin{array}{l}\text { Consignment sale shop, Fueling, } \\
\text { Water supply, Quick-freeze facilities }\end{array}$ & Consignment sale shop & - \\
\hline \multirow{3}{*}{$\begin{array}{l}\text { Locational } \\
\text { condition }\end{array}$} & $\begin{array}{l}\text { Topography } \\
\text { condition }\end{array}$ & $\begin{array}{l}\text { Topography, Geological features, } \\
\text { Depth of water }\end{array}$ & $\begin{array}{l}\text { Topography, Geological features, } \\
\text { Depth of water }\end{array}$ & - \\
\hline & $\begin{array}{l}\text { Geographical } \\
\text { condition }\end{array}$ & $\begin{array}{l}\text { Number of designated harbor, } \\
\text { Neighboring harbor distance, } \\
\text { Accessibility (local road) }\end{array}$ & $\begin{array}{l}\text { Number of designated harbor, } \\
\text { Neighboring harbor distance, } \\
\text { Accessibility (local road) }\end{array}$ & - \\
\hline & $\begin{array}{l}\text { Development } \\
\text { condition }\end{array}$ & $\begin{array}{l}\text { Mining right, Fishery right } \\
\text { (Within harbor limit), } \\
\text { Limited development district, } \\
\text { The ratio of harbor development (\%) }\end{array}$ & $\begin{array}{l}\text { Mining right, Fishery right } \\
\text { (Within harbor limit), } \\
\text { Limited development district, } \\
\text { The ratio of harbor development (\%) }\end{array}$ & \\
\hline \multirow{2}{*}{$\begin{array}{l}\text { Social } \\
\text { economy } \\
\text { condition }\end{array}$} & $\begin{array}{c}\text { Social } \\
\text { condition }\end{array}$ & $\begin{array}{c}\text { Population, Household, } \\
\text { Land usage, Transportation, } \\
\text { Education facilities, } \\
\text { Passenger ship sailing, life zone }\end{array}$ & $\begin{array}{l}\text { Population, Passenger ship sailing, } \\
\text { The scale of life zone }\end{array}$ & $\begin{array}{l}\text { The exclusion of } \\
\text { land usage, } \\
\text { Communication, } \\
\text { Education facilities }\end{array}$ \\
\hline & $\begin{array}{l}\text { Tour } \\
\text { condition }\end{array}$ & $\begin{array}{l}\text { Number of tourist, Tourist Attractions } \\
\text { distance, Accommodations, } \\
\text { Restaurant, Ecological environment }\end{array}$ & $\begin{array}{l}\text { Number of tourist, Tourist Attractions } \\
\text { distance, Ecological environment }\end{array}$ & $\begin{array}{l}\text { The exclusion of } \\
\text { Accommodations, } \\
\text { Restaurant }\end{array}$ \\
\hline
\end{tabular}

\section{-평가항목 선정}

어항기본계획 수립 시 일반적으로 고려되는 기초자료 조사항목을 대상으로 평가항목을 선정하였다(Table 4). 조 사항목 중 대상항 선정에 공통적인 영향을 미치거나 자료 의 신뢰성 제고가 곤란한 항목은 배제시킨다. 평가항목은 수산업 여건, 입지 여건, 사회경제 여건 등 대분류 3 개, 중 분류 8 개, 소분류 24 개 항목으로 분류하여 평가하였다 (Table 5).

\section{-평가항목 분류 및 가중치}

어항개발에 직접적인 영향을 미치는 주요 항목(수산업 현황, 어항시설, 관광, 지리적 여건 등)을 평가항목으로 선 정한다. 평가 등급의 최소 점수는 배점의 $50 \%$ 를 적용시키 며, 지방어항 지정기준(척수, 톤수, 수산인구)은 고배점 부 여하며 개발 및 지역적 여건을 고려하여 지역적 편중현상 억제(지정어항 수, 인근 항과의 거리), 어항으로의 접근성 항목 등에 중요도를 감안하여 배점하였다.
평가항목의 결정에 고려를 해야 할 사항은 대상항 선정 에 공통적인 영향을 미치거나 자료의 신뢰성 제고가 곤란 한 항목은 배제되어야 하며, 어항개발에 직접적인 영향을 미치는 주요 항목을 평가항목으로 포함시켰다.

\section{$A H P$ 기법에 의한 우선순위 산정}

지방어항기준을 만족하는 12 개항에 대하여 전문가 자 문회의 및 $\mathrm{AHP}$ 기법을 이용하여 정량적 평가항목만을 활 용하는 기존방법을 보완하여 정성적인 평가요인들을 포함 시켜 더욱더 정교한 모형을 이용한 우선순위를 산정하였다. 임의적으로 산정했던 평가항목별 배점의 가중치를 전문가 설문조사를 통한 계량적 기법인 $\mathrm{AHP}$ 기법을 사용하여 평 가항목 배점기준의 객관성을 마련하였다.

\section{$-A H P$ 의 기본 개념}

1970 대 초반 T. Saaty에 의하여 개발된 계층분석적 의 사결정방법(Analytic Hierarchy Process: AHP)은 의사결 
Table 5. Assessment weight

\begin{tabular}{|c|c|c|c|}
\hline Category & Item & Classification & Weight \\
\hline \multirow{3}{*}{$\begin{array}{l}\text { Fishery industry } \\
\text { condition }\end{array}$} & Vessel & $\begin{array}{c}\text { Number of vessel and tons, Recreation fishing boat check, } \\
\text { Number of outside vessel }\end{array}$ & 24.0 \\
\hline & Dependence on fishery & $\begin{array}{c}\text { Fishery population, A catch of fish, Fishery rights } \\
\text { (Except for harbor limit) }\end{array}$ & 14.0 \\
\hline & Function facilities & Consignment sale shop & 2.0 \\
\hline \multirow{3}{*}{ Location condition } & $\begin{array}{l}\text { Topography } \\
\text { condition }\end{array}$ & Topography, Geological features, Depth of water & 9.0 \\
\hline & $\begin{array}{l}\text { Geographical } \\
\text { condition }\end{array}$ & $\begin{array}{l}\text { Number of designated harbor, } \\
\text { Neighboring harbor distance, Accessibility }\end{array}$ & 13.0 \\
\hline & $\begin{array}{l}\text { Development } \\
\text { condition }\end{array}$ & $\begin{array}{l}\text { Mining rights, Fishery rights(Within harbor limit), Limited } \\
\text { development district, The ratio of harbor development }(\%)\end{array}$ & 13.0 \\
\hline \multirow[b]{2}{*}{ Social economy } & Social condition & Population, Passenger ship sailing, The scale of life zone & 12.0 \\
\hline & Tour condition & $\begin{array}{l}\text { Number of tourist, Attractions, Accessibility, } \\
\text { Ecological environment }\end{array}$ & 13.0 \\
\hline & & Total & 100.0 \\
\hline
\end{tabular}

Table 6. Measure of pairwise comparison

\begin{tabular}{|c|c|c|}
\hline Status & Definition & Contents \\
\hline 1 & $\begin{array}{l}\text { Equal } \\
\text { importance }\end{array}$ & $\begin{array}{l}\text { Two items have similar contri- } \\
\text { butiveness about some stand- } \\
\text { ards }\end{array}$ \\
\hline 3 & $\begin{array}{l}\text { Moderate } \\
\text { importance }\end{array}$ & $\begin{array}{l}\text { It is slightly preferred one item } \\
\text { to the other by experience and } \\
\text { judgement }\end{array}$ \\
\hline 5 & $\begin{array}{l}\text { Strong } \\
\text { importance }\end{array}$ & $\begin{array}{l}\text { It is strong preferred one item } \\
\text { to the other by experience and } \\
\text { judgement }\end{array}$ \\
\hline 7 & $\begin{array}{l}\text { Very strong } \\
\text { importance }\end{array}$ & $\begin{array}{l}\text { It is very strong preferred one } \\
\text { item to the other by experience } \\
\text { and judgement }\end{array}$ \\
\hline 9 & $\begin{array}{l}\text { Extreme } \\
\text { importance }\end{array}$ & $\begin{array}{l}\text { It is extreme preferred one item } \\
\text { to the other by experience and } \\
\text { judgement }\end{array}$ \\
\hline $2,4,6,8$ & Median & $\begin{array}{l}\text { If comparison value is median } \\
\text { by experience and judgement, } \\
\text { we can use it }\end{array}$ \\
\hline $\begin{array}{l}\text { Reciprocal } \\
\text { number }\end{array}$ & \multicolumn{2}{|c|}{$\begin{array}{l}\text { If } i \text { has specific number about } j, j \text { is reciprocal } \\
\text { number about } i\end{array}$} \\
\hline $1.1 \sim 1.9$ & \multicolumn{2}{|c|}{ (For tied activities) } \\
\hline
\end{tabular}

정의 계층구조를 구성하고 있는 요소간의 쌍대비교(pairwise comparison)에 의한 판단을 통하여 평가자의 지식, 경험 및 직관을 포착하고자 하는 하나의 새로운 의사결정 방법론이다.

이론의 단순성 및 명확성, 적용의 간편성 및 범용성이
라는 특징으로 말미암아 여러 의사결정분야에서 널리 응 용되어 왔으며, 이론구조 자체에 관해서도 활발한 연구가 진행되고 있다.

일반적으로 의사결정문제는 서로 상반된 기준과 불완전 한 정보 및 제한된 자원 하에서 최적의 대안을 선택해야 하는 문제를 내포하고 있으며, 이러한 다수 기준 하에서 평가되는 다수 대안들의 우선 순위를 선정하는 문제를 다 루며, 기존의 의사결정이론체계에서 보면 다속성 의사결 정분석(multi-attribute decision making)의 선호보정이 있 는 모형(compensatory preference model)으로서 그 속성 을 위치시킬 수 있다.

$\mathrm{AHP}$ 는 먼저 상위계층에 있는 요소4)를 기본으로 하위 계층에 있는 각 요소의 가중치를 측정하는 방식을 통하여 상위계층의 요소 하에서 각 하위 요소가 다른 하위 요소 에 비하여 우수한 정도를 나타내주는 수치로 구성되는 쌍 대비교행렬(pairwise comparison matrix)을 작성하고, 이 행렬로부터 고유치 방법(eigenvalue method)을 이용하여 계층의 각 레벨마다 정규화한 하나의 우선순위벡터를 산 출하였다. 마지막으로 계층의 최상위에 위치한 의사결정 의 목적을 달성할 수 있도록 해주는 최하위 단계에 있는 대안들의 상대적인 우선순위를 나타내주는 전체 계층에 대한 하나의 복합우선순위벡터(priority vector)를 산출하 였다.

\section{$-A H P$ 의 적용 절차}

$\mathrm{AHP}$ 는 다수의 대안에 대한 다면적인 평가기준, 다수의

4) 요소(Element): 속성(Attribute)이라고도 하며, 계층에 따라서 전략이 될 수도 있고, 평가항목 또는 기준이 될 수도 있다.

5) Oddershede A, Arias A, Cancino H (2007) Rural development decision support using the Analytic Hierarchy Process, Mathematical and Computer Modelling Vol.46, issues 7-8, October, pp. 1107-1114. 


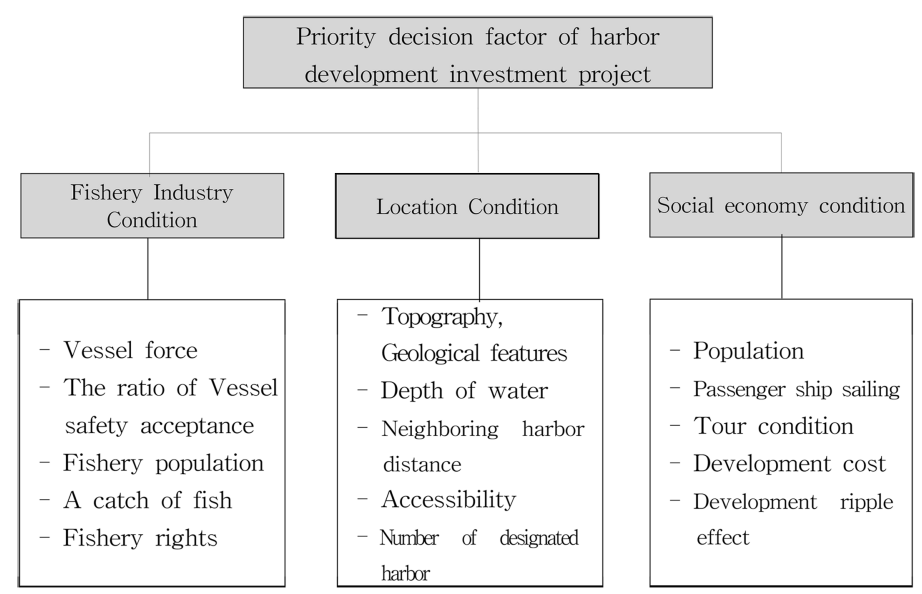

Fig. 1. Priority decision factors for a harbor development investment project.

의사결정주체에 의한 의사결정을 위해 설계된 방법으로써, 의사결정자의 판단을 근거로 정량적인 요소와 정성적인 요소를 동시에 고려함으로써, 의사결정문제의 해결을 위 한 포괄적인 틀을 제공한다. ${ }^{5}$

$$
\begin{aligned}
A & =\left[\begin{array}{ccccc}
1 & a_{12} & a_{13} & \ldots & a_{1 n} \\
a_{21} & 1 & a_{23} & \ldots & a_{2 n} \\
a_{31} & a_{32} & 1 & \ldots & a_{3 n} \\
\vdots & \vdots & \vdots & \ldots & \vdots \\
a_{n 1} & a_{n 2} & a_{n 3} & \ldots & 1
\end{array}\right] \\
A & =\left[\begin{array}{ccccc}
w_{1} / w_{1} & w_{1} / w_{2} & w_{1} / w_{3} & \ldots & w_{1} / w_{n} \\
w_{2} / w_{1} & w_{2} / w_{2} & w_{2} / w_{3} & \ldots & w_{2} / w_{n} \\
\vdots & \vdots & \vdots & \ldots & \vdots \\
w_{n} / w_{1} & w_{n} / w_{2} & w_{n} / w_{3} & \ldots & w_{n} / w_{n}
\end{array}\right]
\end{aligned}
$$

AHP 기법을 통해 다수기준 하에서 평가되는 다수 대안 들의 우선순위를 선정하기 위해서는 먼저, 상위계층에 있 는 평가항목을 기준으로 각 하위 요소가 다른 하위 요소 에 비해 우수한 정도를 나타내주는 수치로 구성되는 쌍대 비교행렬(pairwise comparison matrix)을 작성하게 된다. 작성된 쌍대비교행렬 $\mathrm{A}$ 는 식 (1)과 같이 행렬의 대각을 중심으로 역수의 형태를 취하게 된다. ${ }^{6}$

한 계층 내에서 비교대상이 되는 $\mathrm{n}$ 개 요소의 상대적인 중요도를 $w_{\mathrm{i}}(\mathrm{i}=1, \cdots \mathrm{n})$ 라 하면, 쌍대비교행렬에서의 상대 적인 중요도 a ij는 식 (2)로 나타낼 수 있다.

의사결정자의 의사를 반영한 가중치를 도출하되, 일관
Table 7. Final selection appraisal item

\begin{tabular}{ll}
\hline \multicolumn{1}{c}{ Category } & \multicolumn{1}{c}{ Details } \\
\hline $\begin{array}{l}\text { Fishery } \\
\text { industry } \\
\text { condition (5) }\end{array}$ & $\begin{array}{l}\text { Vessel force, The ratio of Vessel safety } \\
\text { acceptance, Fishery population, } \\
\text { A catch of fish, Fishery rights } \\
\text { Topography, Geological features, Depth } \\
\text { Location } \\
\text { condition (5) }\end{array}$ \\
$\begin{array}{l}\text { of water, Neighboring harbor distance, } \\
\text { Accessibility, Number of designated harbor }\end{array}$ \\
$\begin{array}{l}\text { economy } \\
\text { condition (5) }\end{array}$ & $\begin{array}{l}\text { Population, Passenger ship sailing, } \\
\text { Developmention, Development cost, }\end{array}$ \\
\hline
\end{tabular}

성을 검증하기 위해 식 (3)과 같은 일관성비율(C.R)을 통 하여 구한다.

C.R : C.I / R.I

여기서, C.R : 일관성비율(Consistency Ratio)

C. I : 일관성지수(Consistency Index)

R. I : 난수지수(Random Index)

일관성 비율이 $10 \%$ 이내에 들 경우, 해당 쌍대비교행 렬은 일관성이 있다고 규정한다. 즉, AHP 분석이 일관성 있게 수행되었다고 본다. ${ }^{\text {) }}$

\section{-평가항목 선정}

평가항목의 선정은 기존 연구 결과) 및 문헌조사와 현 지실태조사를 바탕으로 전문가 회의를 통하여 본 연구에 서 대상항인 12 개 항의 특성을 고려할 수 있는 적합한 항 목을 도출하였다(Fig. 1).

6) Cox AM (1996) Proactive Industrial Targeting: An Application of the Analytical Hierarchy Process. M. S. Thesis. Virginia Ploytechnic Institute.

7) Oddershede A (2001) The Analytic Hierarchy Process in Selecting A Telecommunications Company, IV Congreso Chileno de Investigación Operativa, Oct.

8) 제주발전연구원 (2008) 지방어항 배후부지 활용방안, pp. 37-47; 국회예산정책처 (2009) 국가어항개발사업평가, pp. 27-29 참조. 
Table 8. Analysis of high-class weight

\begin{tabular}{|c|c|c|c|}
\hline \multicolumn{3}{|c|}{ Classification } & Weight \\
\hline \multirow{3}{*}{\multicolumn{2}{|c|}{$\begin{array}{l}\text { High class } \\
\text { appraisal item }\end{array}$}} & $\begin{array}{c}\text { Fishery industry } \\
\text { condition }\end{array}$ & 0.3982 \\
\hline & & Location condition & 0.2972 \\
\hline & & $\begin{array}{l}\text { Social economy } \\
\text { condition }\end{array}$ & 0.3046 \\
\hline \multicolumn{3}{|c|}{ Total } & 1.0000 \\
\hline \multicolumn{3}{|c|}{$($ Consistency Index : CI $)$} & 0.0000 \\
\hline \multicolumn{4}{|l|}{0.4500} \\
\hline \multicolumn{4}{|l|}{$\begin{array}{l}0.4000 \\
0.3500\end{array}$} \\
\hline 0.3000 & & 0.2972 & 0.3046 \\
\hline 0.2500 & & & \\
\hline \multicolumn{4}{|l|}{0.2000} \\
\hline \multicolumn{4}{|l|}{0.1500} \\
\hline \multicolumn{4}{|l|}{0.1000} \\
\hline \multicolumn{4}{|l|}{0.0500} \\
\hline 0.0000 & & & \\
\hline
\end{tabular}

Fig. 2. Analysis of the high class graph

앞서 언급하였던 Table 4의 어항기본계획수립 시 일반 적으로 고려되는 기초자료 조사항목을 대상으로 조사항 목 중 대상항 선정에 있어서 공통적인 영향을 미치거나 자료의 신뢰성 제고가 곤란한 항목, 동 연구와의 연관성 이 부족한 항목에 대하여 전문가 자문을 통한 소거법을 이용하여 평가항목을 산정하였다. 기상, 해상과 같은 자연 적 조건 및 육상기능 시설, 광업권 등이 평가항목에서 제 외되었다.

또한, 이 외에는 Delphi Brainstorming Method를 통하 여 ${ }^{9)}$ 본 연구에 적합한 추가 평가항목을 도출하였다. 이는 투자에 있어서 이전까지 비용을 매몰비용(sunk cost)으로 인정하고 향후 투자될 금액 규모의 추정 및 사업으로의 파급효과 등의 경제적인 요인이 포함된다.

최종평가항목은 어항기본계획수립 시 일반적으로 고려 되는 항목 및 Delphi Brainstorming Method를 통하여 추 가된 15 개이며, 이를 평가항목의 유사한 성격을 고려하여 상위계층과 하위계층으로 분류된다.

\section{-평가항목별 가중치 도출}

평가항목별 중요도는 $\mathrm{AHP}$ 분석을 통하여 계량적인 가 중치를 도출하였다. 상위계층 평가항목요인 3 개, 각 상위 계층별 하위계층 평가항목 5 개, 총 15 개 평가항목에 대하 여 그 중요도를 도출했다(Fig. 1).
Table 9. Analysis of fishery industry condition weight

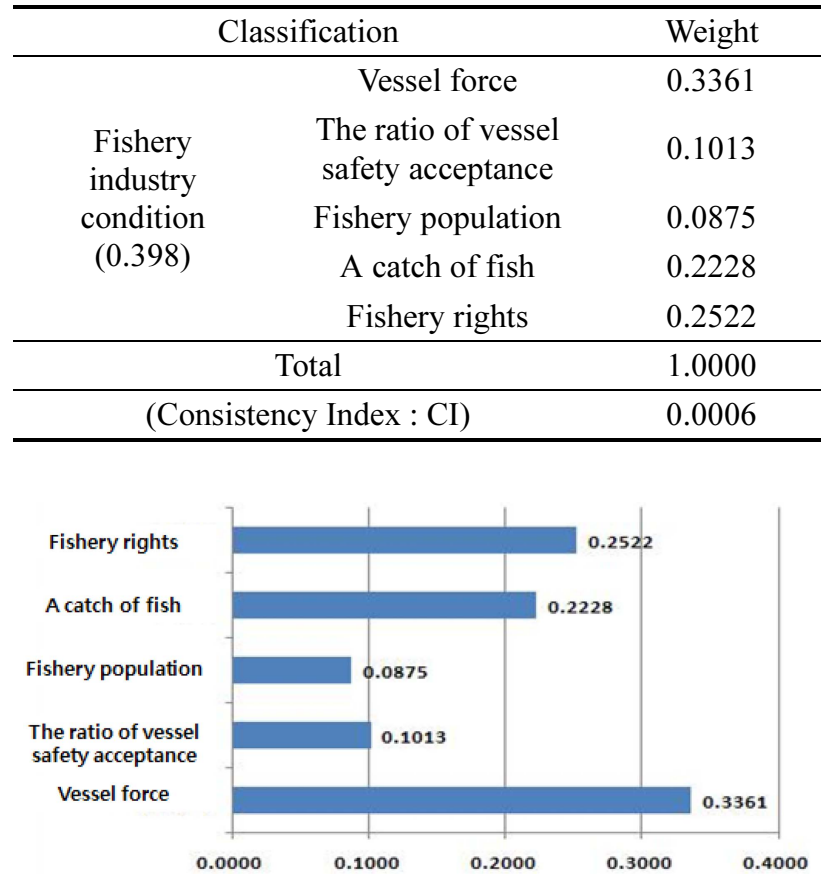

Fig. 3. Analysis of the fishery industry condition weight graph

설문의 구성은 T. Saaty 17점 쌍대척도 사용하며 구성 되었으며, 설문조사는 모형의 특성을 반영하여 학계 및 연 구자의 전문가를 대상으로 총 15 개의 표본을 조사하였으 며, 그 중 1 개에 대하여서는 일관성지수 값이 0.1 보다 높 게 나와 신뢰성이 없는 표본으로 판단되어 유효표본에서 제외되었으며, 최종분석 유효표본은 14 개에 대하여 실시 하였으며, 분석은 프로그램은 Analytic Hierarchy Process 및 Expert choice 11.5를 사용하였다.

\section{3. 실증분석: $\mathbf{A H P}$ 기법 적용 결과}

\section{평가항목 AHP 분석 결과} 상위계층 가중치 분석 결과

상위계층은 수산업 여건이 가장 중요도가 높게 나타나 며, 그 다음으로 사회경제적 여건, 입지 여건 순으로 나타 났다. 이는 지방어항개발에 있어서 해당 어항의 어선 세력 및 어획량, 어업권 등의 수산업 여건이 가장 큰 영향을 미 치는 변수임을 나타낸다.

일관성지수는 0.000 으로 0.1 보다 낮은 결과치가 도출되 어 설문조사의 결과가 일관성이 있으며, 신뢰성을 가지는 결과로 판단된다(Table 8).

9) 해양수산정책 전문가 7 명, 관련 대학교수 4 명, 어항기술 전문가 5 명 등 16 명의 전문가를 활용하여 접근하였음. 
Table 10. Analysis of location condition weight

\begin{tabular}{|c|c|c|}
\hline \multicolumn{2}{|c|}{ Classification } & Weight \\
\hline \multirow{5}{*}{$\begin{array}{l}\text { Location } \\
\text { condition } \\
(0.295)\end{array}$} & $\begin{array}{c}\text { Topography, } \\
\text { Geological features }\end{array}$ & 0.2875 \\
\hline & Depth of water & 0.0662 \\
\hline & $\begin{array}{l}\text { Neighboring } \\
\text { harbor distance }\end{array}$ & 0.3880 \\
\hline & Accessibility & 0.1682 \\
\hline & $\begin{array}{c}\text { Number of designated } \\
\text { harbor }\end{array}$ & 0.0901 \\
\hline & Total & 1.0000 \\
\hline (Cons & acy Index : CI) & 0.0073 \\
\hline
\end{tabular}

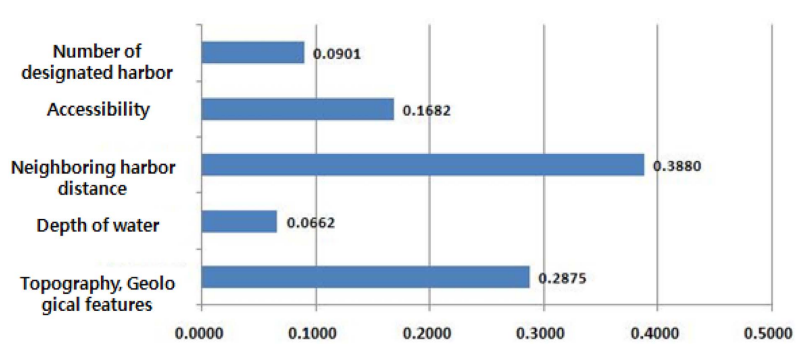

Fig. 4. Analysis of the location condition weight graph

\section{하위계충 가중치 분석 결과 \\ -수산업 여건}

수산업 여건의 하위계층 평가항목의 가중치를 분석한 결과 어선 세력 0.3361 점으로 가장 중요도가 높은 평가항 목으로 도출되었으며 그 다음으로는 어업권(0.2522), 어획 량 $(0.2228)$, 어선안전수용률(0.1013) 순으로 도출되었다.

일관성지수는 0.0006 으로 0.1 보다 낮은 결과치가 도출 되어 설문조사의 결과가 일관성이 있으며, 신뢰성을 가지 는 결과로 판단된다(Table 9).

\section{-입지 여건}

Table 11. Analysis of social economy condition weight

\begin{tabular}{ccc}
\hline & Classification & Weight \\
\hline \multirow{3}{*}{$\begin{array}{c}\text { Social } \\
\text { economy }\end{array}$} & Population & 0.0565 \\
condition & Passenger ship sailing & 0.1951 \\
$(0.307)$ & Tour condition & 0.1993 \\
& Development cost & 0.2955 \\
\hline \multicolumn{2}{c}{ Development ripple effect } & 0.2536 \\
\hline \multicolumn{2}{c}{ Total } & 1.0000 \\
\hline
\end{tabular}

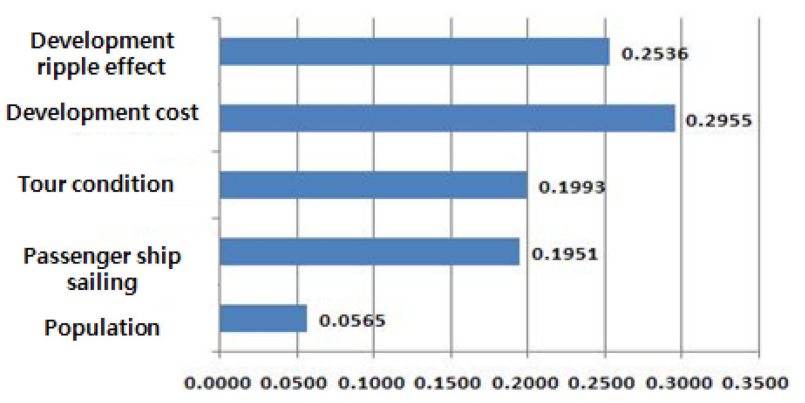

Fig. 5. Analysis of the social economy condition weight graph

입지 여건의 하위계층 평가항목의 중요도 가중치는 인 근항과의 거리가 0.3880 점으로 가장 중요도가 높은 평가 항목으로 나타났으며, 그 다음으로는 지형 및 지질(0.2875), 접근성 $(0.1682)$, 시 · 군지정 어항수(0.0901), 수심(0.0662) 순서로 나타났다.

일관성지수는 0.0073 으로 0.1 보다 낮은 결과치가 도출 되어 설문조사의 결과가 일관성이 있으며, 신뢰성을 가지 는 결과로 판단된다(Table 10).

\section{-사회경제적 여건}

사회경제적 여건의 하위계층 평가항목의 중요도 가중치 는 향후 개발비용규모 평가항목이 0.2955점으로 가장 중요

Table 12. The weighted relative importance for intensity of high rank

\begin{tabular}{|c|c|c|c|c|c|}
\hline \multicolumn{2}{|c|}{$\begin{array}{c}\text { Relative importance is weighted } \\
\text { by fishery industry condition } 0.398\end{array}$} & \multicolumn{2}{|c|}{$\begin{array}{l}\text { Relative importance is weighted } \\
\text { by location condition } 0.297\end{array}$} & \multicolumn{2}{|c|}{$\begin{array}{c}\text { Relative importance is weighted } \\
\text { by social economy condition } 0.305\end{array}$} \\
\hline Vessel force & 0.134 & $\begin{array}{l}\text { Topography, } \\
\text { Geological features }\end{array}$ & 0.085 & Population & 0.017 \\
\hline $\begin{array}{l}\text { The ratio of vessel } \\
\text { safety acceptance }\end{array}$ & 0.040 & Depth of water & 0.020 & Passenger ship sailing & 0.059 \\
\hline Fishery population & 0.035 & $\begin{array}{l}\text { Neighboring } \\
\text { harbor distance }\end{array}$ & 0.115 & Tour condition & 0.061 \\
\hline A catch of fish & 0.089 & Accessibility & 0.050 & Development cost & 0.090 \\
\hline Fishery rights & 0.100 & $\begin{array}{c}\text { Number of } \\
\text { designated harbor }\end{array}$ & 0.027 & $\begin{array}{l}\text { Development } \\
\text { ripple effect }\end{array}$ & 0.077 \\
\hline \multicolumn{2}{|c|}{ Consistency index 0.0006} & \multicolumn{2}{|c|}{ Consistency index 0.0073} & \multicolumn{2}{|c|}{ Consistency index 0.0175} \\
\hline
\end{tabular}


Table 13. Fishery industry condition score

\begin{tabular}{ccccccc}
\hline $\begin{array}{c}\text { Cities and } \\
\text { countries }\end{array}$ & Harbor & Vessel force & $\begin{array}{c}\text { The ratio of vessel } \\
\text { safety acceptance }\end{array}$ & $\begin{array}{c}\text { Fishery } \\
\text { population }\end{array}$ & A catch of fish & Fishery rights \\
\hline Seosan-si & Gudo & 0.355 & 1.000 & 0.153 & 0.245 & 0.070 \\
Seocheon-gun & Dasa & 0.758 & 0.920 & 0.531 & 0.515 & 1.000 \\
Taean-gun & Mandae & 0.900 & 0.613 & 0.854 & 1.000 & 0.018 \\
Dangjin-gun & Dobido & 0.298 & 0.775 & 0.062 & 0.369 & 0.032 \\
Seosan-si & Beolmal & 0.555 & 1.000 & 0.174 & 0.650 & 0.043 \\
Seosan-si & Chang-ri & 0.766 & 1.000 & 0.101 & 0.863 & 0.003 \\
Seosan-si & Wangsan & 0.613 & 1.000 & 0.143 & 0.460 & 0.096 \\
Boryeong-si & Jukdo & 0.251 & 0.627 & 0.430 & 0.203 & 0.007 \\
Seocheon-gun & Jangpo & 0.486 & 0.920 & 0.408 & 0.347 & 0.032 \\
Boryeong-si & Hakseong & 0.432 & 0.627 & 0.649 & 0.421 & 0.000 \\
Dangjin-gun & Waemok & 0.588 & 0.775 & 1.000 & 0.679 & 0.045 \\
Hongseong-gun & Jukdo & 0.267 & 0.000 & 0.083 & 0.273 & 0.098 \\
\hline
\end{tabular}

Table 14. Location condition score

\begin{tabular}{|c|c|c|c|c|c|c|}
\hline $\begin{array}{l}\text { Cities and } \\
\text { countries }\end{array}$ & Harbor & $\begin{array}{c}\text { Topography, } \\
\text { Geological features }\end{array}$ & Depth of water & $\begin{array}{c}\text { Neighboring } \\
\text { harbor distance }\end{array}$ & Accessibility & $\begin{array}{c}\text { Number of } \\
\text { designated harbor }\end{array}$ \\
\hline Seosan-si & Gudo & 0.667 & 0.500 & 1.000 & 0.702 & 1.000 \\
\hline Seocheon-gun & Dasa & 0.500 & 0.700 & 0.096 & 0.702 & 0.750 \\
\hline Taean-gun & Mandae & 0.667 & 0.500 & 0.471 & 0.489 & 0.000 \\
\hline Dangjin-gun & Dobido & 0.333 & 0.500 & 0.058 & 1.000 & 0.917 \\
\hline Seosan-si & Beolmal & 0.333 & 0.000 & 0.522 & 0.000 & 1.000 \\
\hline Seosan-si & Chang-ri & 0.333 & 0.400 & 0.144 & 0.989 & 1.000 \\
\hline Seosan-si & Wangsan & 0.667 & 0.500 & 0.846 & 0.202 & 1.000 \\
\hline Boryeong-si & Jukdo & 0.333 & 0.500 & 0.051 & 0.979 & 0.250 \\
\hline Seocheon-gun & Jangpo & 0.500 & 1.000 & 0.154 & 0.872 & 0.750 \\
\hline Boryeong-si & Hakseong & 0.500 & 0.750 & 0.186 & 0.521 & 0.250 \\
\hline Dangjin-gun & Waemok & 0.500 & 0.500 & 0.122 & 0.957 & 0.917 \\
\hline Hongseong-gun & Jukdo & 1.000 & 0.500 & 0.115 & 0.596 & 0.833 \\
\hline
\end{tabular}

Table 15. Social economy condition score

\begin{tabular}{ccccccc}
\hline $\begin{array}{c}\text { Cities and } \\
\text { countries }\end{array}$ & Harbor & $\begin{array}{c}\text { Number of } \\
\text { population }\end{array}$ & $\begin{array}{c}\text { Passenger ship } \\
\text { sailing }\end{array}$ & Tour condition Development cost & $\begin{array}{c}\text { Development } \\
\text { ripple effect }\end{array}$ \\
\hline Seosan-si & Gudo & 0.456 & 0.286 & 0.721 & 1.000 & 0.956 \\
Seocheon-gun & Dasa & 0.487 & 0.000 & 0.333 & 0.547 & 0.733 \\
Taean-gun & Mandae & 0.318 & 0.000 & 0.333 & 0.509 & 1.000 \\
Dangjin-gun & Dobido & 1.000 & 1.000 & 1.000 & 0.877 & 0.833 \\
Seosan-si & Beolmal & 0.456 & 0.429 & 0.978 & 0.660 & 0.711 \\
Seosan-si & Chang-ri & 0.824 & 0.000 & 0.537 & 0.623 & 0.556 \\
Seosan-si & Wangsan & 0.633 & 0.000 & 0.475 & 0.387 & 0.489 \\
Boryeong-si & Jukdo & 0.787 & 0.000 & 0.833 & 0.509 & 0.789 \\
Seocheon-gun & Jangpo & 0.487 & 0.000 & 0.480 & 0.396 & 0.467 \\
Boryeong-si & Hakseong & 0.583 & 0.000 & 0.436 & 0.472 & 0.556 \\
Dangjin-gun & Waemok & 1.000 & 0.000 & 0.833 & 0.547 & 0.567 \\
Hongseong-gun & Jukdo & 0.515 & 0.000 & 1.000 & 0.717 & 0.833 \\
\hline
\end{tabular}


Table 16. Comparative results of a priority assessment of reserve harbors

\begin{tabular}{cccccccc}
\hline \multirow{2}{*}{$\begin{array}{c}\text { Cities and } \\
\text { countries }\end{array}$} & \multirow{2}{*}{ Harbor } & \multicolumn{3}{c}{ Established method result } & \multicolumn{3}{c}{ AHP analysis result } \\
\cline { 3 - 8 } & & Score & Index & Rank & Score & Index & Rank \\
\hline Seosan-si & Gudo & 84.50 & 1.000 & 1 & 59.83 & 1.000 & 1 \\
Seocheon-gun & Dasa & 78.50 & 0.929 & 2 & 56.04 & 0.937 & 2 \\
Taean-gun & Mandae & 76.80 & 0.909 & 3 & 55.99 & 0.936 & 3 \\
Dangjin-gun & Dobido & 75.50 & 0.893 & 4 & 50.94 & 0.851 & 4 \\
Seosan-si & Beolmal & 74.10 & 0.877 & 5 & 50.52 & 0.844 & 5 \\
Seosan-si & Chang-ri & 72.80 & 0.862 & 6 & 49.82 & 0.833 & 6 \\
Seosan-si & Wangsan & 71.50 & 0.846 & 7 & 49.14 & 0.821 & 7 \\
Boryeong-si & Jukdo & 70.80 & 0.838 & 8 & 36.33 & 0.607 & 10 \\
Seocheon-gun & Jangpo & 67.90 & 0.804 & 9 & 40.35 & 0.674 & 8 \\
Boryeong-si & Hakseong & 66.50 & 0.787 & 10 & 37.67 & 0.630 & 9 \\
Dangjin-gun & Waemok & 76.10 & 0.901 & - & 50.93 & 0.851 & - \\
Hongseong-gun & Jukdo & 70.10 & 0.830 & - & 43.18 & 0.722 & - \\
\hline
\end{tabular}

도가 높으며, 그 다음으로는 개발파급효과규모(0.2536), 관광기반여건(0.1993), 여객선운항횟수(0.1951) 순으로 도 출되었다.

일관성지수는 0.0175 으로 0.1 보다 낮은 결과치가 도출 되어 설문조사의 결과가 일관성이 있으며, 신뢰성을 가지 는 결과로 판단된다(Table 11).

\section{AHP 분석 결과 종합}

\section{각 항목별 가중치}

각 상위계층 평가항목 3 개에 대한 중요도의 가중치와 상위계층에 대한 하위계층 평가항목별 중요도 가중치 결 과를 이용하여 가중된 하위계층 평가항목에 대한 중요도 를 도출하였다 또한 평가항목별 중요도 가중치는 아래 식 과 같이 나타낼 수 있다.

$$
\text { 각 평가항목별 가중치 }=W_{H} \times W_{L}
$$

$W_{H}=$ 상위계층 평가항목 중요도 가중치

$W_{L}=$ 상위계층에 대한 하위계층 평가항목 중요도 가중치

\section{펑가항목별 수치 지수화 -상위계층의 중요도}

먼저 상위 계층의 중요도를 보면 어선 세력이 많은 곳 (0.314)이 최우선으로 나타났으며, 다음 어업권의 활성화 (0.100), 그리고 어획(0.089)의 순으로 나타났다(Table 12).

\section{-수산업 여건 수치 지수화}

이러한 항목의 중요도에 입각하여 각 어항별로 나타난 어항의 여건이 좋은 어항으로는 태안군 만대(0.900), 서산 시 창리(0.766), 그리고 서천군 다사(0.758)의 순으로 나타
났다(Table 13).

\section{- 입지여건 수치 지수화}

어항이 위치한 지리적 여건이 우수한 어항으로는 홍성 군 죽도(1.00)로 가장 유리한 입지적 조건을 갖춘 것으로 나타났으며 그 다음으로 서산시 구도(0.667), 태안군 만대 (0.667)가 동일하게 나타났으며, 그 다음으로는 서천군 다 사(0.500), 서천군 장포(0.500), 보령시 학성, 당진군 왜목 등의 순으로 나타났다(Table 14).

\section{-사회경제적여건 수치 지수화}

사회경제적인 여건은 어항에서 이루어지고 있는 국민들 의 경제활동의 역동성을 기초로 하며 이는 인구 수에 비 례한 행정적 여건과도 어느 정도 비례하고 있음을 알 수 있다. 그 결과를 살펴보면 당진군 도미비도와 왜목이 1000 으로 가장 높은 것으로 나타났는데 이는 우리나라의 서비스 산업의 발달로 휴양시설 및 레저시설이 현대화하 여 도시에서의 출입 인구가 빈번하기 때문인 것으로 사료 된다(Table 15).

충청남도 지방어항 지정후보항 우선순위산정을 위한 기 존 방법에 의한 평가 결과와 $\mathrm{AHP}$ 분석기법에 의한 평가 결과를 비교해보면 Table 16 같이 도출되었다.

기존 방법에 의한 평가 결과와 AHP 분석기법에 의한 평가 결과는 각 항의 지수값의 차이가 있으며, 점수화를 하였을때 $\mathrm{AHP}$ 분석 결과 낮은 점수가 도출되며, 상대적 인 순위는 6순위까지 일치하는 것으로 평가된다. 따라서 구도항, 다사항, 만대항, 도비도항, 벌말항 순으로 지방어 항 지정 우선순위를 평가되었다.

\section{4. 결 론}


국가 및 지방어항의 개발은 대부분 몇 개의 후보항 중 일부를 지정하여 투자를 하게된다. 이 과정에서 평가항목 결정 및 평가항목별 배점은 투자의 우선순위를 결정하는 매우 중요한 요인이다.

기존의 평가항목은 정량적인 부분만을 활용하고 있으며, 평가를 실시하는데 있어서 임의적으로 평가항목별 배점의 가중치를 부여하고 있는 문제점이 있어 객관성에 대한 문 제가 발생한다.

본 연구는 충청남도 지방어항 사례를 이용하여 기존 방 법에서 사용되고 있던 평가항목 및 정성적인 평가항목들 을 검토하여 항목을 선정하였으며, 더욱더 객관적이고 정 교한 평가항목별 배점의 가중치를 부여하기 위하여 전문 가설문조사를 통한 계량적 기법인 AHP 기법을 사용하여 평가항목 배점의 가중치를 도출하였다.

또한, 12 개의 후보항을 대상으로 어항의 지정기준, 지역 별 입지여건, 어선안전 수용율, 어항 이용실태 등을 종합 적으로 분석하여 지방어항 지정후보항의 투자우선순위를 제시하였으며, 기존의 어항의 투자에 이용되는 방법과 결 과를 비교하였다.

그러나 본 연구에서 평가항목을 선정하는데 지리적 여 건, 주변 해양환경시설 및 주변 인프라 등 어항을 건설하 는데 있어서 고려해야 할 다양한 요인을 모두 포함하지 않은 것은 연구의 한계라고 할 수 있다. 사회가 복잡해지 고 경제가 발달할수록 어느 한 요인을 분석하는데는 이를 둘러싼 여러 가지 부수적인 요소가 작용하기 때문에 이에 대한 추가적인 요소도 포함되어야 하기 때문이다.

그럼에도 불구하고 $\mathrm{AHP}$ 기법을 이용하여 평가항목의 중요도를 객관적으로 도출한 이러한 평가방법은 향후 타 국가어항 및 지방어항 개발, 기타관련 분야에 많은 도움을 줄 수 있을 것으로 판단된다.

\section{사 사}

본 연구의 완성도를 위해 귀중한 의견을 주신 심사위원
들과 논문게재과정에서 도움을 주신 편집위원회에 감사드 립니다.

\section{참고문헌}

국회예산정책처 (2009) 국가어항개발사업평가. 국회예산정책 처, $52 \mathrm{p}$

권희자 (2006) 스포츠산업의 정책 지향을 위한 우선투자요인 분석. 체육학박사 학위논문, 상명대학교, $169 \mathrm{p}$

김명진 (2003) 계층화 분석법(AHP)에 의한 한국의 적정 국 방비 수준 결정에 관한 연구. 경영학박사 학위논문, 경희 대학교, $132 \mathrm{p}$

원광희, 박효기 (2003) 충청북도 도로사업의 투자우선순위 기준연구. 충북개발연구원, $79 \mathrm{p}$

임성일 (1999) 지방자치단체의 두자순위 결정에 관한 연구. 한국지방정부학회, 지방정부연구 33(1):44-55

충청남도 (2009) 지방어항지정 타당성 조사. 충청남도, $152 \mathrm{p}$ 제주발전연구원 (2008) 지방어항 배후부지 효율적 활용방안. 제주발전연구원, $90 \mathrm{p}$

한광석, 이종훈 (2005) 어항개발의 경제성 평가분석 방법론 에 관한 연구. 한국해양수산개발원, $246 \mathrm{p}$

한광석, 성상봉 (2009) 국가어항개발사업 모니터링 조사보고 서, 한국해양수산개발원, $280 \mathrm{p}$

Cox, AM (1996) Proactive industrial targeting: an application of the analytical hierarchy process. M.S. Thesis, Virginia Polytechnic Institute and State Universty, 346 p

Oddershede A, Arias A, Cancino H (2007) Rural development decision support using the Analytic Hierarchy Process. Math Comput Model 46(7-8):1107-1114

Oddershede A (2001) The Analytic Hierarchy Process in selecting a telecommunications company. In: Proceedings of IV Congreso Chileno de Investigación Operativa, Universidad de Talca, Curició, Chile, 10-12 Oct 2001 